\title{
Comparison of different control strategies for classical swine fever using emergency vaccination and rapid PCR testing by using a Monte-Carlo simulation model
}

\author{
Julia Brosig', Imke Traulsen', Sandra Blome², Klaus Depner² and Joachim Krieter ${ }^{1}$ \\ ${ }^{1}$ Institute of Animal Breeding and Husbandry, Christian-Albrechts-Universität zu Kiel, Kiel, Germany, ${ }^{2}$ Institute of \\ Diagnostic Virology, Friedrich-Loeffler-Institute, Greifswald - Insel Riems, Germany
}

\begin{abstract}
Whenever an outbreak of classical swine fever has occurred in the European Union (EU), the basic control measures have usually been supplemented by preventive culling. This strategy has led to a great number of culled pigs and is discussed by general public and politics from both ethical and economic points of view. Emergency vaccination has been deemed to be an alternative control measure for some time now. PCR testing also provides a possible future strategy, since this method would allow a rapid and reliable testing of pigs in the vicinity of an outbreak farm. In this study, a spatial and temporal Monte-Carlo simulation model was used to compare alternative control strategies based upon these two measures (»Emergency Vaccination", »Test To Slaughter", »Test To Control« and "Vaccination in conjunction with Rapid Testing «) with the current control strategy. Two regions for investigation with different farm densities were used in the model. In a region with a low farm density, the basic EU control measures seemed to be sufficient to control an epidemic. In a region with a high farm density, additional measures would be necessary. »Emergency Vaccination« in a $3 \mathrm{~km}$ application zone and »Traditional Control « reached the same level of infected farms. Both »Test To Slaughter« and »Test To Control« combined with preventive culling led to a lower number of infected farms compared to the sole preventive culling strategy. The alternative control measures can reduce the number of culled farms significantly compared to »Traditional Control«.
\end{abstract}

Archiv Tierzucht 56 (2013) 100, 988-1004

doi: $10.7482 / 0003-9438-56-100$

Corresponding author:

Julia Brosig; email: jbrosig@tierzucht.uni-kiel.de

Institute of Animal Breeding and Husbrandy, Christian-Albrechts-Universität zu Kiel, Olshausenstraße 40, 24098 Kiel, Germany

() 2013 by the authors; licensee Leibniz Institute for Farm Animal Biology (FBN), Dummerstorf, Germany. This is an Open Access article distributed under the terms and conditions of the Creative Commons Attribution 3.0 License

(http://creativecommons.org/licenses/by/3.0/).
Received: 4 March 2013

Accepted: 8 November 2013

Online: 14 November 2013 
Keywords: Classical swine fever, simulation study, control strategies, emergency vaccination, rapid testing

Abbreviations: CSF: classical swine fever, LSM: least square means, rRT-PCR: real-time reverse transcriptionpolymerase chain reaction

\section{Introduction}

Classical swine fever (CSF) is an OIE-listed disease of domestic pigs and wild boar which causes considerable economic losses (Edwards et al. 2000). It is a highly contagious viral disease caused by the CSF virus, a member of the genus Pestivirus of the family Flaviviridae (Moennig 2000). Classical swine fever is distributed globally. In Europe outbreaks have occurred in domestic pig holdings in Lithuania, Serbia, Bulgaria, Russia and Slovakia in the last five years. Additionally the virus continues to recur in the wild boar population of several EU member states (OIE 2013).

In the case of an outbreak of CSF in the EU, its control is carried out according to Council Directive 2001/89/EC (Anonymous 2001). To prevent further spread, several control measures are carried out, such as the culling of all pigs on the outbreak farm, the establishment of protection and surveillance zones and contact tracing. Additional measurements can be applied wherever and whenever required by the epidemiological situation. One of these is for example the preventive culling of pigs on farms in the surrounding of an outbreak farm. Council Directive 2001/89/EC stipulates a radius of $500 \mathrm{~m}$ around an outbreak site but sometimes the radius is extended e.g. in the epidemics in Belgium 1997 (Mintiens et al. 2001), in the Netherlands 1997/1998 (Elbers et al. 1999) or in Germany 2006 (Anonymous 2006). This current strategy leads to a widespread destruction of healthy animals and is therefore controversial both from an ethical and an economical point of view. Emergency vaccination is deemed to be an alternative measure which also reduces the susceptible population. Prophylactic vaccination against CSF is strictly prohibited in the EU but the current legislation allows an emergency vaccination as an additional tool to control and eradicate CSF. If CSF has been confirmed and if it threatens to spread especially in an area with high pig density, this measure can be ordered (Anonymous 2001). The vaccination can be carried out either with a conventional, modified live vaccine or a marker vaccine. Most attenuated live vaccines are based on the lapinised China-strain (C-strain) of the CSF virus. These vaccines are highly efficacious. After two to five days after vaccination, animals are protected against infection and are most likely immune throughout their economic life (Moennig 2000, Blome et al. 2006). Furthermore, vaccination with the C-strain induces almost sterile immunity. Seven days after vaccination pigs show neither viraemia nor virus excretion (Anonymous 2003, Van Oirschot 2003). Using the C-strain, horizontal virus transmission is prevented already at the day of vaccination (Dewulf et al. 2004). However, the attenuated live vaccines have the great disadvantage that the antibodies induced after vaccination cannot be distinguished from those after a field-virus infection. It is not possible to distinguish vaccinated from infected animals and so the requirement for the absence of antibodies against the CSF virus cannot be fulfilled. However, marker vaccines have been developed to try to solve this problem. The CSF virus has three proteins inducing detectable antibodies. These are on the one hand the non-structural protein NS3 and on the other hand the envelope proteins $\mathrm{E}^{\mathrm{rns}}$ and E2. Since 
E2 is the major immunogen, the first generation of these marker vaccines are so-called E2 subunit vaccines. They are based on baculovirus expressed glycoprotein E2 of the CSF virus (van Rijn et al. 1996, Moormann et al. 2000). Pigs vaccinated with these E2 subunit vaccines develop only E2-specific antibodies so it is possible to distinguish vaccinated from infected animals with an ELISA that detects antibodies against $E^{\text {rns }}$ (Floegel-Niesmann 2001). However, these first marker vaccines have shown several problems concerning efficacy compared to the conventional, modified live vaccine. They are less protective and the immune response is delayed. Not until 14 to 21 days after vaccination are the animals fully protected (Hulst et al. 1993, Bouma et al. 2000, Uttenthal et al. 2001). The two developed E2 subunit vaccines require however a booster vaccination. Moreover, it was found that the prevention of horizontal and vertical spread of the CSF virus is not sufficient (Dewulf et al. 2002) and that the E ${ }^{\text {rns }}$-ELISA does not yet provide satisfactory sensitivity and specificity (Floegel-Niesmann 2001). In addition, pathogen detection has improved in regard to sensitivity and capacity. Real-time reverse transcription-polymerase chain reaction ( $r R T-P C R)$ is the most sensitive method for the detection of the CSF virus and makes a genetic differentiation between vaccinated and infected animals possible (Blome et al. 2011). Here, the differentiation is based on genome sequence varieties between vaccine strains and field virus. With an E2 subunit vaccine, which does not contain any virus genome, a CSF specific rRT-PCR protocol can be used. A positive test result would be a proof for an infection with field virus (Anonymous 2010). In case of the C-vaccine, a vaccine virus-specific rRT-PCR protocol is necessary. Multiplex rRT-PCR assays for simultaneous detection of CSF virus and the vaccine strain are newly developed (Zhao et al. 2008, Hoffman et al. 2009, Leifer et al. 2009). In the very unlikely event of a CSF field virus infection shortly after vaccination, the rRT-PCR might fail to discriminate clearly between vaccinated pigs and pigs infected with a field virus after vaccination. Nevertheless, combination of the new C-vaccine specific rRT-PCR with sequencing will ensure that these animals are identified (Leifer et al. 2009, Blome et al. 2011). During major disease outbreaks a large amount of samples need to be tested. Using sample pooling, RNA extraction robots and real-time PCR machines with a 96- or 384-sample platform, high throughput seems feasible (Depner et al. 2007, Hoffmann et al. 2011). rRT-PCR would allow a rapid and reliable testing of all pigs on farms in the vicinity of an outbreak farm and avoid preventive culling (Beer et al. 2007, Greiser-Wilke et al. 2007). Hence, Rapid Testing seems to be a possible CSF control measure.

The objective of this study was to evaluate possible future CSF control strategies and to compare them with the current control strategy. The future strategies consisted of emergency vaccination, Rapid Testing using rRT-PCR and a combination of these two alternative measures. To describe the spread and control of CSF a spatial and temporal Monte-Carlo simulation model was used.

\section{Material and methods}

\section{The simulation model}

The simulation model described the spread and control of the CSF virus between individual farms in a given region on daily basis. It was a spatial and temporal approach using a Monte- 
Carlo simulation to model epidemics. The enclosed contact structure and the virus emission were based on a foot-and-mouth disease simulation model (Traulsen et al. 2010) and were adapted to CSF. The herd incubation period amounted to 27 days on average (lognormal distribution with a mean of 3.3 and standard deviation of 0.1 ) (Karsten et al. 2005b). The virus was able to spread by local spread, as well as by animal, person and vehicle contact. The transport of piglets from a farrowing farm to a fattening farm was implemented in the model as direct contact. Farrowing farms either sold all their animals directly to a certain number of fattening farms (contract sale) or the animals were randomly allocated by an animal hauler to any other fattening farm (trade). Indirect contacts in terms of the veterinarian and animal feed vehicles were solved as a routing problem. Routes for the indirect contacts started at a given depot, visited a certain number of farms (veterinarian: 10 farms, feed vehicle: 15 farms) and returned to the depot. Farms within a route were arranged in ways that the travelling distances were minimised. Therefore the Nearest-Neighbour-Algorithm was used (Traulsen et al. 2010). An infectious farm could transmit the virus to the next farm on the route with a decreasing probability by an exponential function. The probability depends on the route position behind the infectious farm and the transmission probabilities of the contact type. The transmission probabilities are summarised in Table 1. We orientated towards Karsten et al. (2005a) and Boklund et al. (2009) and adapted the parameters to our model. Local spread occurred in circles around an outbreak farm ( $\leq 250 \mathrm{~m}, 250-500 \mathrm{~m},>500-1000 \mathrm{~m}$ ) with a decreasing probability at increasing distance (Karsten et al. 2007). A sensitivity analysis was performed to investigate the reaction of the simulation model to changes in the input data. An epidemic started with the infection of the index farm (set by the user), all other farms were in the state »susceptible«. Once a farm had been infected, it ran through the states »infectious«, »clinical signs«, »diagnosed» and »culled». In the case of Rapid Testing a farm could also be in the state »empty« after all fattening pigs had been delivered to the slaughterhouse.

The simulation program was written in the object-oriented language $\mathrm{C}++$. Routines from the NAG C library (NAG 2002) were used to generate random numbers.

Table 1

Transmission probabilities for the different contact types and local spread within the simulation model

\begin{tabular}{ll}
\hline Transmission probabilities & \\
\hline Animal contact & 0.95 \\
Vehicle contact & 0.50 \\
Person contact & 0.60 \\
Local spread & \\
$<250 \mathrm{~m}$ & 0.0130 \\
$250-500 \mathrm{~m}$ & 0.0043 \\
$500-100 \mathrm{~m}$ & 0.0023 \\
\hline
\end{tabular}

\section{Farm data}

In the present study two investigation regions with different farm densities were examined, both had a size of $908 \mathrm{~km}^{2}$. The farm data were derived from the Farm Structure Survey 2003 (Forschungsdatenzentrum 2005). The farms were located by their $x$ - and $y$-coordinates 
and depending on their animal composition they were classified according to farm type (farrowing farm, fattening farm or farrow-to-finishing farm). The first region was located in Northern Germany. It consisted of 728 farms, of which 69 were farrowing farms, 382 were fattening farms and 277 were farrow-to-finishing farms. Hence, this region had a farm density of 0.8 farms $/ \mathrm{km}^{2}$. The second region consisted of 2733 farms (517 farrowing farms, 1444 fattening farms and 772 farrow-to-finishing farms) and had a farm density of $3.0 \mathrm{farms} / \mathrm{km}^{2}$. This fictitious region was used to investigate the influence of the farm density on the control measures. To avoid an edge effect in the simulation an additional region with a radius of 10 $\mathrm{km}$ was located around the real investigation regions. Otherwise, the number of preventive culled, vaccinated and tested farms would have been underestimated. The radius of $10 \mathrm{~km}$ equated the maximum size of the application zones of the control measures. In both regions a farrowing farm in the centre of the region was set as an index case to obtain a »worst-case scenario».

\section{The control strategies}

Six basic control strategies (Restriction Zone, Traditional Control, Emergency Vaccination, Test To Slaughter, Test To Control and Vaccination in conjunction with Rapid Testing) were examined. In all strategies, with the exception of Restriction Zone and Traditional Control, a $3 \mathrm{~km}$ application zone and a $10 \mathrm{~km}$ application zone of the control measure was established. Furthermore, vaccination was carried out either with a modified live vaccine (C-vaccine) or with a marker vaccine (E2 subunit vaccine). This led to a total of 26 considered control strategies, which are summarised in Table 2.

\section{Restriction Zone}

This control strategy consisted of the minimum control measures according to the EU guidelines in case of an CSF outbreak (Anonymous 2001). It included culling of all outbreak farms, the establishment of protection zones within a radius of $3 \mathrm{~km}$ and surveillance zones within a radius of $10 \mathrm{~km}$ around the outbreak farms and contact tracing during the previous 30 days. In protection and surveillance zones (restriction zones), the movement and transport of pigs was prohibited. In the simulation model, the user was able to set a percentage value according to which extend the movement restrictions are limited. It is known from previous outbreaks that despite the establishment of restriction zones infections occur via the transport of pigs (Terpstra \& de Smit 2000). For this reason, a value of 90 percent was determined as a basis in this study.

The following control strategies were based on this strategy.

\section{Traditional Control}

In addition to the basic measures of Restriction Zone, preventive culling was applied in this strategy within a radius of $1 \mathrm{~km}$ around the outbreak farms. The legislation allows preventive culling of farms within a radius of at least $500 \mathrm{~m}$ from the outbreak (Anonymous 2001), but in previous epidemics, e.g. in the Netherlands 1997/1998 (Elbers et al. 1999) or in Germany 2006 (Anonymous 2006), the radius was extended. 


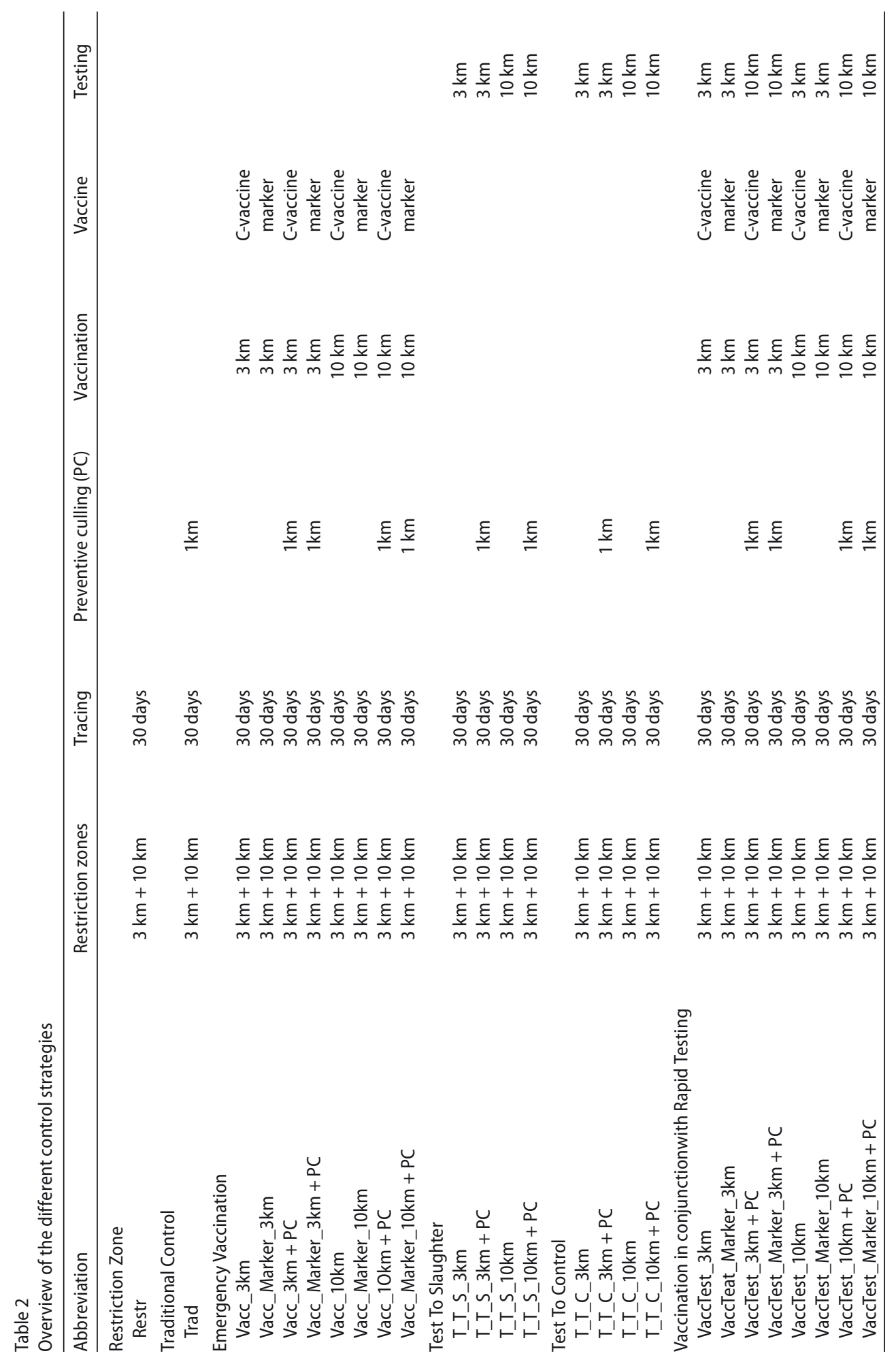




\section{Emergency vaccination}

In this study, the fattening farms and farrow-to-finishing farms within the application zone were vaccinated either with a C-vaccine or with an E2 subunit vaccine. Vaccination started three days after detection of the first farm and in the case of secondary outbreaks two days after detection. This time delay was attributed to EU permission and provision of vaccines and vaccination teams. The delay of three respectively two days represents a $»$ best case scenario«. To prevent outward spread, vaccination started outside of application zone and was continued towards the centre. After an average of four days (normal distribution with a mean of 4 and a standard deviation of 0.5 ), the pigs were immune against CSF if they were vaccinated with a $\mathrm{C}$-vaccine. If vaccinated with an $\mathrm{E} 2$ subunit vaccine, they were immune on average after 21 days (normal distribution with a mean of 21 and a standard deviation of 0.7). A vaccination efficacy of $98 \%$ was assumed for both vaccines. Furthermore, the assumption was made that one vaccination team could vaccinate three farms per day and that 10 teams were available so that a maximum of 30 farms could be vaccinated per day.

\section{Test To Slaughter}

This control strategy makes rRT-PCR useful as an additional measure. rRT-PCR is the most powerful technique for early detection of the CSF virus. In comparison with virus isolation in a cell culture, the virus can be detected earlier after infection and for a longer period (Paton et al. 2000, Dewulf et al. 2004). Because of the possibility to test pooled samples a great number of animals can be tested in a short period. rRT-PCR offers the potential of rapid testing with a high sensitivity (Greiser-Wilke et al. 2007).

In the application zones, all finishing pigs ready for slaughter were tested using rRT-PCR before transport to the slaughterhouse. Rapid testing was carried out before each delivery of slaughter pigs. The PCR results were available after $24 \mathrm{~h}$. When the test was negative, the pigs were slaughtered, otherwise the farm was awarded the status »diagnosed « and then "culled«. If the last pig on the farm was slaughtered, the farm was given the status »empty«. A test sensitivity of $99 \%$ was assumed (Depner et al. 2007, Zhao et al. 2008, Leifer et al. 2011).

This strategy does not comply with the current legislation but it constitutes a possible future control strategy for CSF.

\section{Test To Control}

Like the strategy Test To Slaughter, this strategy is based on rRT-PCR and is not currently in accordance with the EU directive. Here, rapid testing was used as a control measure. After CSF had been confirmed on a farm, all finishing pigs on farms in the application zone were tested immediately and repeatedly seven days after the first test. If the test was positive, the farm was classified as »diagnosed «, followed by the status »culled«. Otherwise finishing pigs that were ready for slaughter could be delivered to the slaughterhouse.

\section{Vaccination in conjunction with Rapid Testing}

The measures of Emergency Vaccination and Test To Slaughter were combined in this strategy. The vaccination was carried out as described in 2.3.3. and additionally all slaughter pigs were tested using rRT-PCR before the transport to the slaughterhouse. Here, the genetic differentiation of vaccinated and infected animals was used. The differentiation is based on 
genome sequence varieties between vaccine strains and field virus so that both attenuated live vaccines and marker vaccines could be used (Beer et al. 2007, Leifer et al. 2009).

\section{Output analysis}

For each control strategy the simulation model was run for 2500 iterations. To evaluate the strategies the mean number of infected, overall culled (farms culled after diagnosis plus preventive culled farms), preventive culled, vaccinated and tested farms were considered. These output variables were count data and therefore not normally distributed. A generalised linear model was fitted to the response variables as a function of control strategy and farm density:

$$
\log \left(E\left(Y_{i j}\right)\right)=\beta_{0}+\text { control strategy }_{i}+\text { farm density }_{j}+\left(\text { control strategy } \times \text { farm density }_{i j}\right.
$$

The GLIMMIX procedure of the SAS program package (SAS 2006; SAS Institute Inc., Cary, NC, USA) was used for this. The best model fit was obtained by a negative binomial distribution and a log-link function. The ratio of Pearson Chi-Square and the degrees of freedom were close to one for all response variables. Type III statistics were used to examine the significance of the main factors and the interactions. Analyses were done via least square means (LSM) on log-scale. Pair-wise differences between LSM were examined with a t-test. Since an adjustment for multiple testing was necessary, a Bonferroni adjustment was carried out. The results are presented by the inverse transformed values of the LSM.

\section{Results}

The effects of the different control strategies for both investigated regions are shown in Figure 1. In this case, the application radius amounted to $3 \mathrm{~km}$ and a C-vaccine was used for vaccination. In the low-density region, no significant differences were observed in the number of infected farms between the control strategies. A range of 7.7 to 8.4 farms was infected. In all control strategies, except Traditional Control (14.5 culled farms), the number of culled farms was equal to the number of infected farms. The high-density region presented a slightly different picture. On average 80.9 farms were infected and culled with the Restriction Zone strategy. In contrast, the control strategies Trad, Vacc_3km, T_T_C_3km and VaccTest_3km led to a significantly lower number of infected farms (range of 32.4 to 34.5).T_T_S_3km also decreased the number of infected farms significantly compared to the Restriction Zone strategy, but with 40.0 infected farms there was also a significant difference from the other control strategies. The Traditional Control strategy led to the highest number of culled farms (126.1). In all other strategies, only the infected farms were culled and therefore the number of culled farms was in accordance with the number of infected farms.

Table 3 shows the effect of an increased application radius. Applying the control measures in an enhanced radius of $10 \mathrm{~km}$ resulted in a decreased number of infected farms in both investigation regions. However, in the low-density investigation region the decrease was very small. However, in the high-density region especially the strategy T_T_S_10km reduced the number of infected farms significantly from 39.9 to 32.7 .

The influence of additional preventive culling in a $1 \mathrm{~km}$ radius on the number of infected and culled farms in the high-density region is shown in Figure 2. In all alternative control 


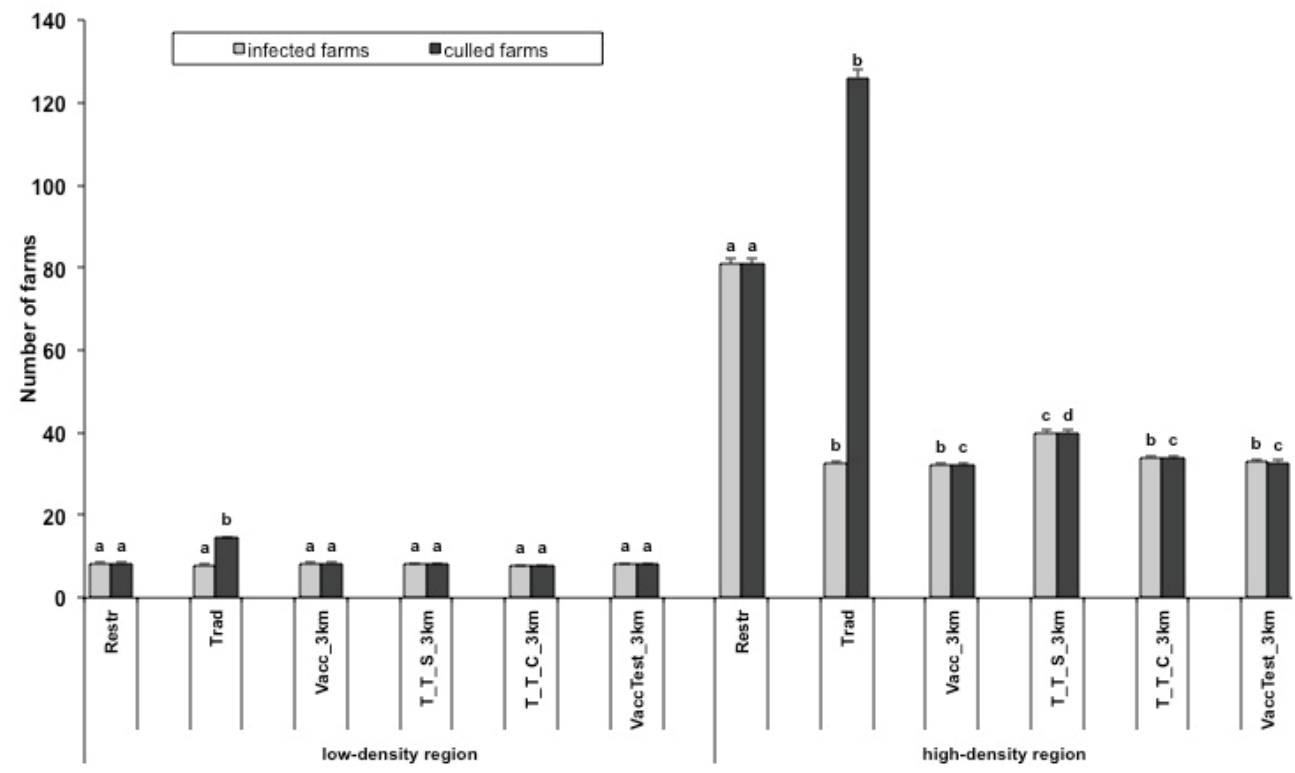

Figure 1

LSM number of infected and culled farms and their standard error for both regions for control strategies Restr, Trad, Vacc_3km, T_T_S_3km, T_T_C_3 $3 \mathrm{~km}$ and VaccTest_3km (Different letters indicate significant differences within number of infected respectively culled farms and region $\mathrm{a}=0.05$ )

Table 3

LSM number of infected farms for both regions for the six control strategies using a $3 \mathrm{~km}$ or $10 \mathrm{~km}$ application radius

\begin{tabular}{llccc}
\hline \multicolumn{2}{c}{ Low-density region } & \multicolumn{2}{c}{ Infected farms } \\
\hline & $3 \mathrm{~km}$ & $10 \mathrm{~km}$ & $3 \mathrm{~km}$ & $10 \mathrm{~km}$ \\
Restr & 8.4 & & 80.9 & \\
& 7.9 & $7.6 \mathrm{a}$ & 32.6 & $29.4 \mathrm{a}$ \\
Vacc & $8.4 \mathrm{a}$ & $7.6 \mathrm{a}$ & $32.4 \mathrm{a}$ & $32.7 \mathrm{~b}$ \\
T_T_S & $8.3 \mathrm{a}$ & $39.9 \mathrm{a}$ & $31.7 \mathrm{a}$ \\
T_T_C & $7.7 \mathrm{a}$ & $7.6 \mathrm{a}$ & $34.3 \mathrm{a}$ & $29.0 \mathrm{~b}$ \\
VaccTest & $8.2 \mathrm{a}$ & $7.4 \mathrm{a}$ & $33.0 \mathrm{a}$ & \\
\hline
\end{tabular}

Different letters indicate significant differences within control strategy and region, $a=0.05$.

strategies (Vacc_3km+PC, T_T_S_3km+PC, T_T_C_3km+PC and VaccTest_3km PC), adding preventive culling slightly decreased the number of infected farms to a level of 30 respectively 29. Again Test To Slaughter showed the strongest effect and Vaccination Zone showed no significant difference. Additional preventive culling resulted in a significantly higher number of culled farms in all control strategies. For example, Vacc_3km+PC showed 104.3 culled farms compared to 31.7 culled farms without preventive culling (Vacc_3 $\mathrm{km}$ ). In the lowdensity region, the addition of preventive culling again resulted in a very slightly decreased or unchanged number of infected farms. In all alternative control strategies about 14 farms were culled (data not shown). 

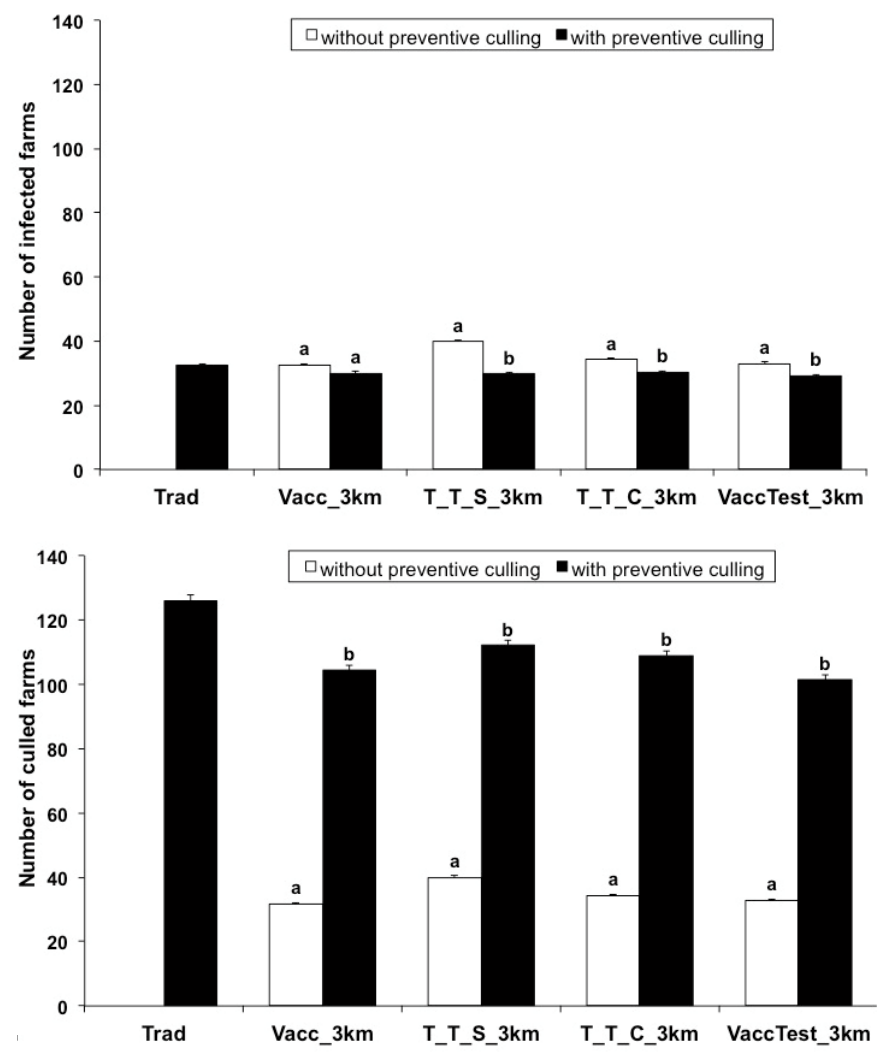

Figure 2

LSM number of infected and culled farms and their standard error for control strategies Trad, Vacc_3km, T_T_S_3km, T_T_C_3km and VaccTest_3km without and with preventive culling for the high-density region (Different letters indicate significant differences within control strategy, $a=0.05$ )

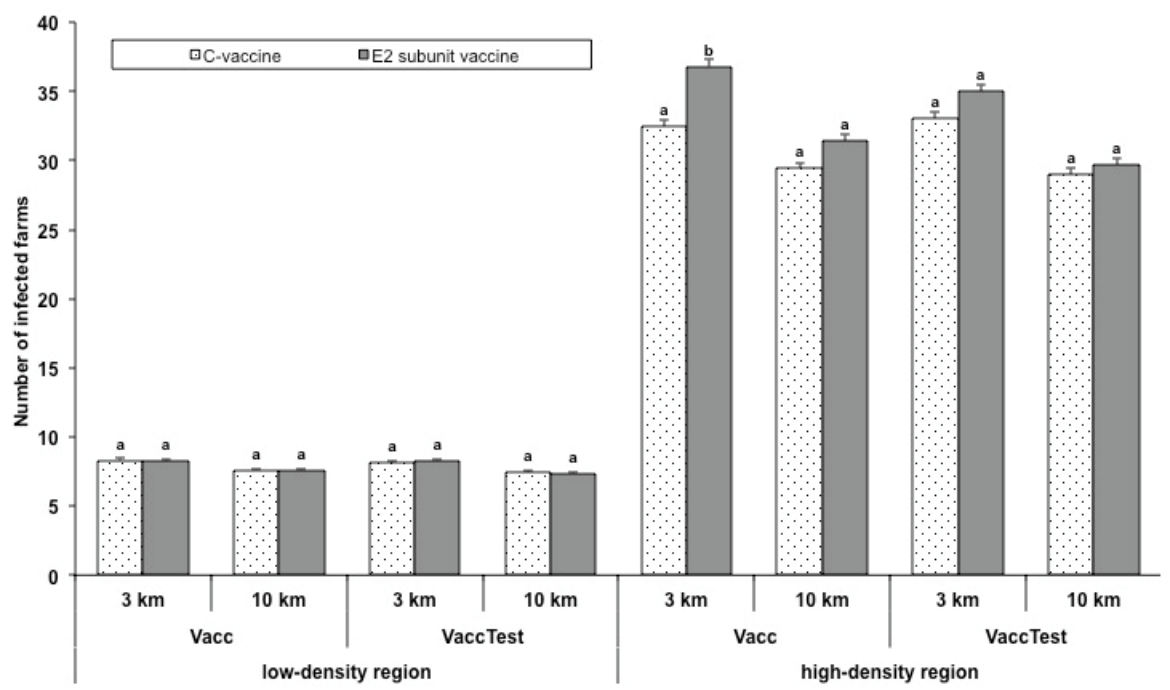

Figure 3:

LSM number of infected farms and their standard error using a C-vaccine or an E2 subunit vaccine in the control strategies Vacc and VaccTest either in a $3 \mathrm{~km}$ or a $10 \mathrm{~km}$ application radius (Different letters indicate significant differences within region, control strategy and application radius, $\mathrm{a}=0.05$ ) 
Using an E2 subunit vaccine compared to a C-vaccine showed no difference in the number of culled farms in the low-density region (Figure 3). This was valid for both strategies Vacc and VaccTest, each with a $3 \mathrm{~km}$ application zone and a $10 \mathrm{~km}$ application zone. In the highdensity region, epidemics eradicated with the Vacc_Marker_3km strategy resulted in 36.8 infected farms and therefore in significantly more infected farms than those vaccinated with a C-vaccine (Vacc_3km: 32.4). An increased number of infected farms was seen in the $10 \mathrm{~km}$ application zone by using the E2 subunit vaccine but to a much smaller and not significant extent. VaccTest_Marker_3km and VaccTest_Marker_10km also led to a slightly increased number of infected farms compared to vaccination with a C-vaccine, but the difference was very small especially in the $10 \mathrm{~km}$ radius.

Table 4

Number of culled, thereof preventive culled respectively culled after a positive PCR result, vaccinated and tested farms for the low-density region

\begin{tabular}{|c|c|c|c|c|c|}
\hline \multirow[b]{2}{*}{$\begin{array}{l}\text { Control } \\
\text { strategy }\end{array}$} & \multirow[b]{2}{*}{$\begin{array}{l}\text { Culled } \\
\text { farms }\end{array}$} & \multicolumn{2}{|c|}{ Low-density region } & \multirow[b]{2}{*}{$\begin{array}{l}\text { Vaccinated } \\
\text { farms }\end{array}$} & \multirow[b]{2}{*}{$\begin{array}{c}\text { Tested } \\
\text { farms }\end{array}$} \\
\hline & & $\begin{array}{l}\text { Preventiv } \\
\text { culled farms }\end{array}$ & $\begin{array}{l}\text { Farms culled } \\
\text { after test }\end{array}$ & & \\
\hline Restr & 8.4 & & & & \\
\hline Trad & 14.5 & 9.1 & & & \\
\hline Vacc_3km & 8.3 & & & 61.7 & \\
\hline Vacc_3km + PC & 13.7 & 8.5 & & 48.6 & \\
\hline Vacc_10km & 7.2 & & & 345.6 & \\
\hline T_T_S_3km & 8.2 & & 0.5 & & 42.4 \\
\hline T_T_S_3km + PC & 14.4 & 9.0 & 0.2 & & 32.9 \\
\hline T_T_S_10km & 7.6 & & 0.8 & & 273.6 \\
\hline T_T_C_3km & 7.7 & & 0.7 & & 57.8 \\
\hline T_T_C_3 km +PC & 14.5 & 8.9 & 0.3 & & 54.7 \\
\hline T_T_C_10km & 7.6 & & 1.1 & & 348.4 \\
\hline VaccTest_3km & 8.1 & & 0.2 & 57.9 & 39.5 \\
\hline VaccTest_3km + PC & 13.8 & 8.5 & 0.1 & 48.9 & 31.7 \\
\hline VaccTest_10km & 7.2 & & 0.4 & 319.3 & 259.8 \\
\hline
\end{tabular}

Table 5

Number of culled, thereof preventive culled respectively culled after a positive PCR result, vaccinated and tested farms for the high-density region

\begin{tabular}{|c|c|c|c|c|c|}
\hline \multirow[b]{2}{*}{$\begin{array}{l}\text { Control } \\
\text { strategy }\end{array}$} & \multirow[b]{2}{*}{$\begin{array}{l}\text { Culled } \\
\text { farms }\end{array}$} & \multicolumn{2}{|c|}{ High-density region } & \multirow[b]{2}{*}{$\begin{array}{c}\text { Vaccinated } \\
\text { farms }\end{array}$} & \multirow[b]{2}{*}{$\begin{array}{l}\text { Tested } \\
\text { farms }\end{array}$} \\
\hline & & $\begin{array}{l}\text { Preventiv } \\
\text { culled farms }\end{array}$ & $\begin{array}{l}\text { Farms culled } \\
\text { after test }\end{array}$ & & \\
\hline Restr & 80.7 & & & & \\
\hline Trad & 126.1 & 109.7 & & & \\
\hline Vacc_3km & 31.7 & & & 612.3 & \\
\hline Vacc_3km + PC & 104.3 & 88.9 & & 474.1 & \\
\hline Vacc_10km & 29.4 & & & 2656.3 & \\
\hline T_T_S_3km & 39.9 & & 11.1 & & 612.4 \\
\hline T_T_S_3km + PC & 112.0 & 95.6 & 2.2 & & 392.5 \\
\hline T_T_S_10km & 32.7 & & 11.2 & & 2504.3 \\
\hline T_T_C_3km & 34.2 & & 10.5 & & 597.5 \\
\hline T_T_C_3km + PC & 108.9 & 92.4 & 2.7 & & 472.6 \\
\hline T_T_C_10km & 31.7 & & 11.1 & & 2369.5 \\
\hline VaccTest_3km & 32.8 & & 3.3 & 598.1 & 543.7 \\
\hline VaccTest_3km + PC & 101.3 & 86.3 & 0.8 & 454.2 & 379.6 \\
\hline VaccTest_10km & 29.5 & & 6.0 & 2528.0 & 2420.7 \\
\hline
\end{tabular}


The numbers of culled, thereof preventively culled respectively after a positive PCR result, vaccinated and tested farms for the low-density region are presented in Table 4 and for the high-density region in Table 5. All in all, the number of farms affected (culled, vaccinated and tested farms) by the control measures was significant lower in the low-density region. The Restriction Zone strategy led to the lowest number of affected farms both in the low- and the high-density investigation regions. Nevertheless, in the high-density region Restriction Zone led to the highest number of infected farms (80.7). Most farms were involved using Vaccination in conjunction with Rapid Testing when vaccination and rapid testing were carried out, followed by solely vaccinating or testing. If preventive culling was a part of the control strategy, the number of culled farms was highest and at the same time the number of vaccinated and tested farms decreased. Thus, the number of farms culled after testing also decreased. If the size of the application zone was increased from 3 to $10 \mathrm{~km}$, the number of vaccinated, respectively tested farms increased significantly, especially in the region with the high farm density. In both investigation regions, the number of vaccinated farms respectively tested farms both within the $3 \mathrm{~km}$ and in particular within the $10 \mathrm{~km}$ application zone were a lot higher compared to the number of culled farms using Traditional Control. In the low-density region 8.4 farms were culled in the Restriction Zone strategy. Using emergency vaccination or rapid PCR testing within a $3 \mathrm{~km}$ radius, 61.7 farms were vaccinated, respectively 57.8 farms were tested. In the high-density region even 612.3 farms were vaccinated, respectively 597.5 farms were tested. The alternative control strategies reduced the number of culled farms from 80.7 to 31.7 (Emergency Vaccination), respectively 34.2 (Test To Control).

\section{Discussion}

The simulation showed that control strategies using vaccination and rapid testing could be alternatives to the current control measures. Beside the control strategy, the region had an influence on the success of CSF control. The two different investigation regions resulted in a considerably different number of infected and therefore affected farms. These results are in compliance with the findings of Nissen \& Krieter (2003), who identified the density as an important risk factor for the spread of CSF. Evaluating the control strategies, it is necessary to take into account that a simulation model is a simplification of a real system. Assumptions have to be made which can lead to limitations.

\section{Low-density region}

In the low-density region with a low farm density of $0.8 \mathrm{farms} / \mathrm{km}^{2}$, all considered control strategies had approximately the same efficiency. This is in line with a simulation study examining CSF in Denmark (Boklund et al. 2009). In a region with a low farm density the Restriction Zone strategy with culling of all outbreak farms, establishment of restriction zones with movement restrictions and contact tracing seemed to be sufficient, since additional measures such as preventive culling, vaccination or rapid testing did not lead to a significantly lower number of infected farms. At the same time, the number of affected farms would increase with those additional measures. The establishment of the restriction zones meant that the only possible route of infection left was local spread in the neighbourhood. 
When the farm density was low, there was a very small number of neighbouring farms around an outbreak farm and therefore the additional measures could not further reduce the number of susceptible farms. It has to be taken into account that in the simulations, movement restrictions were followed only at $90 \%$ and that with a stricter following the Restriction Zone strategy is even more successful (Brosig et al. 2012). Thulke et al. (2011) even showed with their simulation model that these basic measures might be sufficient to control most CSF outbreaks.

\section{High-density region}

In the high-density region with a density of $3.0 \mathrm{farms} / \mathrm{km}^{2}$, the Traditional Control strategy and the alternative control strategies were able to reduce the number of infected farms significantly compared to the Restriction Zone strategy. This was due to the high number of neighbouring farms. Mangen et al. (2002) also showed that in densely populated regions the alternative control measures (preventive culling and emergency vaccination) were more effective than the basic strategy. Traditional Control, Vacc_3km and VaccTest_3km led to approximately the same number of infected farms. However, T_T_C_3km and especially T_T_S_3km were not as efficient. Thulke et al. (2011) also examined a control strategy using rapid testing as a control measure. They also found that this strategy was more successful than the basic strategy (movement restrictions) and less or as successful as a preventive culling strategy (depending on the efficiency of movement restrictions). Both strategies using rRTPCR did not reduce the number of susceptible farms as preventive culling or vaccination did, so that there was still a risk that farms in the application zone became infected. Using Test To Control, the test was carried out immediately after confirming CSF on an outbreak farm. Thus, the already infected farms could be found quickly and further spread could be avoided. The number of infected farms was in the same order of magnitude as those of Traditional Control, Vacc_3km and VaccTest_3km (Figure 1). In contrast, Test To Slaughter showed a significantly higher number of infected farms. This was due to the longer period before the test was carried out, right before transport to the slaughterhouse.

In a region with a high farm density, the number of infected farms increased using an E2 subunit vaccine instead of a C-vaccine. If animals were vaccinated with this marker vaccine, a stable immunity against the CSF virus developed later and therefore the animals were susceptible for a longer time period. The present results confirm the findings of the EFSA (2009). In this study, fewer infected farms ensued with a vaccine effective four days after vaccination compared to one that is not effective until 14 days after. The fact that the difference between these two vaccines was not even greater was due to the earlier diagnosis of infected animals in a zone in which vaccination is carried out. This is because of the visual inspection of each animal during the vaccination procedure. Thus, Mangen et al. (2001) assumed a higher probability of detection in the first 14 days after infection when already infected farms were vaccinated compared to susceptible farms.

Increasing the application radius to $10 \mathrm{~km}$ reduced the number of infected farms in all alternative control strategies and again the reduction was the highest in Test To Slaughter. However, the relatively low decrease in the number of infected farms was attended by a very sharp increased number of vaccinated, respectively tested farms. Vaccination and/or rapid testing was able to reduce the number of culled farms provided that preventive culling 
was avoided. Beside preventive culling, the welfare culling of finishing pigs that are ready for slaughter but are not allowed to leave the farm is problematic from both ethical and economic points of view. Previous epidemics showed that welfare culling was the highest cost element in severe cases (Saatkamp et al. 2000). In the present study, welfare culling is not included so that the number of overall culled farms is underestimated. This applies to Restriction Zone and Traditional Control as well as to the alternative control strategies. An exact determination of the number of farms culled for welfare reasons would be favourable, since rapid testing alone as a measure in a possible future control strategy could avoid or reduce welfare culling (Greiser-Wilke et al. 2007).

\section{Simulation model - assumptions and limitations}

In the simulation different assumption had to be made to simplify the model. This concerns the farm data, the contact structure and the implemented control strategies and needs to be taken into account examining the results. Particular attention must be paid to the number of farms that need to be tested and/or vaccinated. It was assumed that 30 farms per day can be vaccinated/tested and that the PCR results were available after 24 hours. However, especially in the high-density area and with a $10 \mathrm{~km}$ application radius, an extremely large number of affected farms occurred. It must be critically questioned and further examined whether the implementation is logistically possible. In discussions with experts it became apparent that in such an extreme situation like a CSF outbreak it should be possible to bring enough veterinarians together to conduct the vaccination respectively the taking of blood samples. Preventive culling, which is included in the current control strategy, is also accompanied by considerable personal effort. Previous outbreaks have shown that it is possible to manage a great number of affected farms. In the CSF outbreak 1997/1998 in the Netherlands 429 infected farms were eradicated and additionally 1225 farms were preventive culled (Terpstra \& de Smit 2000). Using the alternative control measures, the limiting factor would probably be the PCR testing. Although a high test throughput seems feasible (Depner et al. 2007, Hoffmann et al. 2011), with such a great number of blood samples the laboratory capacities would not be sufficient. Therefore, a $10 \mathrm{~km}$ application radius seems to be unrealistic at the moment. As with preventive culling, emergency vaccination and rapid testing will be accompanied by considerable personnel and material effort. Thus, when comparing the different control measures, it is also essential to take into account the economic consequences.

\section{References}

Anonymous (2001) Council Directive 2001/89/EC of 23 October 2001 on Community measures for the control of classical swine fever. Official Journal of the European Communities L 316/5

Anonymous (2003) Diagnostic Techniques and Vaccines for Foot-and-Mouth Disease, Classical Swine Fever, Avian Influenza and some other important OIE List A Diseases. Report of the Scientific Committee on Animal Health and Animal Welfare. Adopted 24-25th April 2003, European Commission, Health and Consumer Protection Directorate-General, Directorate C - Scientific Opinions, C2 - Management of scientific committees; scientific co-operation and networks

Anonymous (2006) 2006/346/EC: Commission Decision of 15 May 2006 concerning certain protection measures relating to classical swine fever in Germany and repealing Decision 2006/274/EC. Official Journal of the European Union L 128/10 
Anonymous (2010) Expert opinion on vaccine and/or diagnostic banks for major animal diseases. Strategic planning options for emergency situations or major crises. (SANCO/7117/2010). European Commission, Health and Consumers Directorate-General, Directorate D - Animal Health and Welfare, D1-Animal Health and Standing Committees

Beer M, Reimann I, Hoffmann B, Depner K (2007) Novel marker vaccines against classical swine fever. Vaccine 25, 5665-5670

Blome S, Gabriel C, Staubach C, Leifer I, Strebelow G, Beer M (2011) Genetic differentiation of infected from vaccinated animals after implementation of an emergency vaccination strategy against classical swine fever in wild boar. Vet Microbiol 153, 373-376

Blome S, Meindl-Böhmer A, Loeffen W, Thuer B, Moennig V (2006) Assessment of classical swine fever diagnostics and vaccine performance. Rev Sci Tech Off Int Epiz 25, 1025-1038

Boklund A, Toft N, Alban L, Uttenthal A (2009) Comparing the epidemiological and economic effects of control strategies against classical swine fever in Denmark. Prev Vet Med 90, 180-193

Bouma A, De Smit AJ, De Jong MCM, De Kluijver EP, Moormann RJM (2000) Determination of the onset of the herd-immunity induced by the E2 sub-unit vaccine against classical swine fever virus. Vaccine 18, 1374-1381

Brosig J, Traulsen I, Krieter J (2012) Control of Classical Swine Fever Epidemics Under Varying Conditions With Special Focus on Emergency Vaccination and Rapid PCR Testing. Transbound Emerg Dis (doi:10.1111/ tbed.12028)

Depner K, Hoffmann B, Beer M (2007) Evaluation of real-time RT-PCR assay for the routine intra vitam diagnosis of classical swine fever. Vet Microbiol 121, 338-343

Dewulf J, Laevens H, Koenen F, Mintiens K, de Kruif A (2002) An E2 sub-unit marker vaccine does not prevent horizontal or vertical transmission of classical swine fever virus, Vaccine 20, 86-91

Dewulf J, Koenen F, Mintiens K, Denis P, Ribbens S, de Kruif A (2004) Analytical performance of several classical swine fever laboratory diagnostic techniques on live animals for detection of infection. J Virol Methods $119,137-143$

Dewulf J, Laevens H, Koenen F, Mintiens K, de Kruif A (2004) Efficacy of E2-sub-unit marker and C-strain vaccines in reducing horizontal transmission of classical swine fever virus in weaner pigs. Prev Vet Med $65,121-133$

Edwards S, Fukusho A, Lefèvre PC, Lipowski A, Pejsak Z, Roehe P, Westergaard J (2000) Classical swine fever: the global situation. Vet Microbiol 73, 103-119

EFSA (2009) Scientific Opinion of the Panel on Animal Health and Welfare on a request from Commission on "Animal health safety of fresh meat derived from pigs vaccinated against Classic Swine Fever«. The EFSA Journal 933, 1-15

Elbers ARW, Stegeman A, Moser H, Ekker HM, Smak JA, Pluimers FH (1999) The classical swine fever epidemic 1997-1998 in the Netherlands: descriptive epidemiology. Prev Vet Med 42, 157-184

Floegel-Niesmann G (2001) Classical swine fever (CSF) marker vaccine: Trial III. Evaluation of discriminatory ELISAs. Vet Microbiol 83, 121-136

Forschungsdatenzentrum (2005) Research Data Centers of the Federal Statistical Office and the statistical offices of the Länder. Agricultural Structure Survey. Available at: www.forschungsdatenzentrum.de [last assessed 26.11.2013]

Greiser-Wilke I, Blome S, Moennig V (2007) Diagnostic methods for detection of Classical swine fever virus Status quo and new developments. Vaccine 25, 5524-5530

Hoffmann B, Beer M, Reid SM, Mertens P, Oura CAL, van Rijn PA, Slomka MJ, Banks J, Brown IH, Alexander DJ, King DP (2009) A review of RT-PCR technologies used in veterinary virology and disease control: Sensitive and specific diagnosis of five livestock diseases notifiable to the World Organisation for Animal Health. Vet Microbiol 139, 1-23 
Hoffmann B, Blome S, Bonilauri P, Fernández-Piñero J, Greiser-Wilke I, Haegeman A, Isaksson M, Koenen F, LeBlanc N, Leifer I, Le Potier MF, Loeffen W, Rasmussen TB, Stadejek T, Ståhl K, Tignon M, Uttenthal Å, van der Poel W, Beer M (2011) Classical swine fever virus detection results of a real-time reverse transcription polymerase chain reaction ring trial conducted in the framework of the European network of excellence for epizootic disease diagnosis and control. J Vet Diagn Invest 23, 999-1004

Hulst MM, Westra DF, Wensvoort G, Moormann RJ (1993) Glycoprotein E1 of hog cholera virus expressed in insect cells protects swine from hog cholera. J Virol 67, 5435-5442

Karsten S, Rave G, Krieter J (2005a) Monte Carlo simulation of classical swine fever epidemics and control: I. General concepts and description of the model. Vet Microbiol 108, 187-198

Karsten S, Rave G, Krieter J (2005b) Monte Carlo simulation of classical swine fever epidemics and control: II. Validation of the model. Vet Microbiol 108, 199-205

Karsten S, Rave G, Teuffert J, Krieter J (2007) Evaluation of Measures for the Control of Classical Swine Fever Using a Simulation Model. Arch Tierz 50, 92-104

Leifer I, Blome S, Beer M, Hoffmann B (2011) Development of a highly sensitive real-time RT-PCR protocol for the detection of Classical swine fever virus independent of the $5^{\prime}$ untranslated region. J Virol Methods 171, 314-317

Leifer I, Depner K, Blome S, Le Potier MF, Le Dimna M, Beer M, Hoffmann B (2009) Differentiation of C-strain »Riems« or CP7_E2alf vaccinated animals from animals infected by classical swine fever virus field strains using real-time RT-PCR. J Virol Methods 158, 114-122

Mangen MJJ, Jalvingh AW, Nielen M, Mourits MCM, Klinkenberg D, Dijkhuizen AA (2001) Spatial and stochastic simulation to compare two emergency-vaccination strategies with a marker vaccine in the 1997/1998 Dutch Classical Swine Fever epidemic. Prev Vet Med 48, 177-200

Mangen MJJ, Nielen M, Burrell AM (2002) Simulated effect of pig-population density on epidemic size and choice of control strategy for classical swine fever epidemics in The Netherlands. Prev Vet Med 56, 141-163

Mintiens K, Deluyker H, Laevens H, Koenen F, Dewulf J, De Kruif A (2001) Descriptive Epidemiology of a Classical Swine Fever Outbreak in the Limburg Province of Belgium in 1997. J Vet Med B 48, 143-149

Moennig V (2000) Introduction to classical swine fever: virus, disease and control policy. Vet Microbiol 73, 93-102

Moormann RJM, Bouma A, Kramps JA, Terpstra C, De Smit HJ (2000) Development of a classical swine fever subunit marker vaccine and companion diagnostic test. Vet Microbiol 73, 209-219

NAG (2002) The NAG C Library Manual, Mark 7. The Numerical Algorithms Group Ltd, Oxford, UK

Nissen B, Krieter J (2003) Relative importance of risk factors concerning the introduction and spread of classical swine fever and foot-and-mouth disease in Germany. Arch Tierz 46, 535-545

OIE (2013) Disease information. http://www.oie.int/wahis_2/public/wahid.php/Countryinformation/ Countryreports [last accessed 26.11.2013]

Paton DJ, McGoldrick A, Bensaude E, Belak S, Mittelholzer C, Koenen F, Vanderhallen H, Greiser-Wilke I, Scheibner H, Stadejek T, Hofmann M, Thuer B (2000) Classical swine fever virus: a second ring test to evaluate RT-PCR detection methods. Vet Microbiol 77, 71-81

Saatkamp HW, Berentsen PBM, Horst HS (2000) Economic aspects of the control of classical swine fever outbreaks in the European Union. Vet Microbiol 73, 221-237

SAS (2006) SAS User's Guide, Version 9.1. SAS Institute Inc., Cary, NC, USA

Terpstra C, de Smit AJ (2000) The 1997/1998 epizootic of swine fever in the Netherlands: control strategies under a non-vaccination regimen. Vet Microbiol 77, 3-15

Thulke HH, Eisinger D, Beer M (2011) The role of movement restrictions and pre-emptive destruction in the emergency control strategy against CSF outbreaks in domestic pigs. Prev Vet Med 99, 28-37

Traulsen I, Rave G, Krieter J (2010) Sensitivity analysis of a stochastic simulation model for foot and mouth disease. Archi Tierz 53, 529-544 
Uttenthal Å, Le Potier MF, Romero L, De Mia GM, Floegel-Niesmann G (2001) Classical swine fever (CSF) marker vaccine: Trial I. Challenge studies in weaner pigs. Vet Microbiol 83, 85-106

Van Oirschot JT (2003) Vaccinology of classical swine fever: from lab to field. Vet Microbiol 96, 367-384

Van Rijn PA, Bossers A, Wensvoort G, Moormann RJM (1996) Classical swine fever virus (CSFV) envelope glycoprotein E2 containing one structural antigenic unit protects pigs from lethal CSFV challenge. J Gen Virol 77, 2737-2745

Zhao JJ, Cheng D, Li N, Sun Y, Shi Z, Zhu QH, Tu C, Tong GZ, Qiu HJ (2008) Evaluation of a multiplex real-time RT-PCR for quantitative and differential detection of wild-type viruses and C-strain vaccine of Classical swine fever virus. Vet Microbiol 126, 1-10 